\title{
THE GENETICAL CONTROL OF SELF-INCOMPATIBILITY IN RYEGRASSES
}

\author{
M. J. LAWRENCE," C. H. FEARON,* M. A. CORNISH* AND M. D. HAYWARD + \\ * Department of Genetics, University of Birmingham, Birmingham B15 2TT \\ † Welsh Plant Breeding Station, Plas Gogerddan, Aberystwyth SY23 3EB
}

Received 28.iv.83

\section{SUMMARY}

\begin{abstract}
We have shown in previous papers that self-incompatibility in Lolium perenne and $L$. multiflorum is determined, as in the other grasses that have been adequately investigated, by a pair of multi-allelic genes and that the control of the pollen phenotype is gametophytic (Cornish, Hayward and Lawrence, 1979; Fearon, Hayward and Lawrence, 1983). We also attempted to show in these papers that the claim by Spoor (1976) and Hay (1978) that self-incompatibility in these species was determined by at least three genes was based on data which was open to question on technical grounds. Despite this criticism, however, McCraw and Spoor $(1983 a, b)$ have repeated this claim. In the present paper we show that their claim cannot be supported by their data because (i) they have not fully classified their pollinations into grades of compatibility; (ii) they have not attempted to fit a specific genetical model to their data; and (iii) the probability that their data, even if this is taken at face value, is consistent with their claim is very small. We argue, therefore, that these data and the conclusions that are drawn are too untrustworthy to be taken seriously. Since the only other case, not superseded by more recent work, is also vulnerable to this criticism (Murray, 1979), there is no justification for supposing that self-incompatibility, either in the genus Lolium or in the grasses in general, is determined by more than two genes. It follows, therefore, that an attempt by Østerbye, Larsen and Lundqvist (1980) to argue that our conclusions are consistent with those of Spoor and $\mathrm{McCraw}$ (née Hay) is unnecessary.
\end{abstract}

Most of the self-incompatible grasses that have been adequately investigated appear to possess a two-locus, multi-allelic system with gametophytic control of the pollen phenotype in which incompatibility occurs when $S-Z$ pairs in the pollen are matched by the same combination of alleles in the stigma. Our own work on Lolium perenne and L. multiflorum shows that this is also the case in the ryegrasses (Cornish, Hayward and Lawrence, 1979; Fearon, Hayward and Lawrence, 1983). Others, however, have come to a different conclusion. Thus Spoor (1976) with L. perenne, Hay (1978) with $L$. multiflorum and McCraw and Spoor $(1983 a, b)$ with these two species and $L$. rigidum have also argued that self-incompatibility in these ryegrasses is controlled by at least three multi-allelic loci and, in the most recent pair of papers, that not all alleles in the pollen have to be matched by those in the stigma for incompatibility to occur. While cases are known of species of different genera within the same family apparently possessing different incompatibility systems (Crowe, 1971; Varopoulos, 1979) and even of different species within the same genus (Pandey, 1962; Abdulla and Hermsen, 1971), these results with ryegrass, if upheld, would constitute the first examples of different systems occurring within the same species.

Now there is no doubt that, in principle, particular populations of a species which possesses a multi-locus system of self-incompatibility could 
segregate for less than the full number of loci, for the minimum requirement for compatibility is that just one locus should continue to segregate. Thus a population of a self-incompatible species with, say, a three-locus system could segregate for only two loci. If material was sampled from such a population and subjected to the usual analysis, the species would erroneously appear to possess a two-locus system. The existence of the third locus would then be discovered only when material was sampled from a population in which none of the incompatibility loci had become homozygous. Hence, at first sight, as suggested by Østerbye, Larsen and Lundqvist (1980), one explanation of the discrepancy between our own conclusions, on the one hand, and those of Spoor and McCraw, on the other, would be simply that in the material we have analysed, less than the full number of loci have been segregating. It is difficult to sustain this argument, however, in view of the fact that we have deliberately chosen as parents of the families we have analysed material that has very diverse provenance (Cornish et al., loc cit.; Fearon et al., loc cit.; Cornish, 1979; Scarrott, 1981).

We believe the explanation for this discrepancy between the two sets of results lies elsewhere, for three chief reasons. First, though both Spoor and $\mathrm{McCraw}$ and ourselves have used the same technique of aniline blue fluorescence microscopy to examine the behaviour of pollen on the stigma, the former have recognised two classes of pollination only, namely, incompatible and compatible pollinations. Yet any system of self-incompatibility of the gametophytic type will give three classes, incompatible, fully compatible and a third class of partially compatible pollination in which a mixture of incompatible and compatible pollen can be observed on the stigma. Though they have clearly seen such pollinations in their material, for it is on this that their conclusion that control of the pollen phenotype in ryegrass is gametophytic is correctly based, McCraw and Spoor $(1983 b)$ believe that the "subdivision of compatible pollinations could be fraught with uncertainty" and cite Lundqvist (1961) and Hayman (1956) in support of this opinion. Apart from the fact that Lundqvist's and Hayman's view of this matter was given before the UV fluorescence method was in general use, it is possible to distinguish partially compatible pollinations from the other kinds of pollination with a high degree of accuracy and repeatability. Thus, all but two of the misclassified pollinations in the experiments with $L$. perenne described by Cornish et al., (loc cit.) involved the misclassification of half-compatible with three-quarters compatible pollinations, and vice versa; and all misclassifications were of this type in our work with L. multiflorum (Fearon et al., loc cit.). Furthermore, although it is obviously more difficult to distinguish between grades of partial compatibility than between these and either fully compatible or incompatible pollinations, over 80 per cent of all partially compatible pollinations in our experiments were correctly classified on sight. It is, therefore, simply not true to argue that the subdivision of compatible pollinations is fraught with difficulty. On the contrary, to fail to distinguish between types of compatible pollination is to forego critical information, which can be obtained. in no other way, about the number of alleles which plants have in common. It must be emphasised, however, that the subdivision of compatible pollinations is possible only when great care is taken to ensure that the pollen used is both fresh and viable; if this is not done, pollinations may be misclassified or unclassifiable. 
Second, it is important to fit a specific model to data when carrying out a genetical analysis of an incompatibility system. Thus, any model, irrespective of the number of loci involved, gives a specific pattern of pollinations between genotypes against which the data can be compared. Only if the simplest reasonable model fails comprehensively to account for the observed pattern of pollinations should any attempt be made to fit a more complex model to the data. If analysis is not carried out this way, any misclassified pollinations or contaminant plants will go undetected, whose presence will inevitably lead to the erroneous conclusion that the genetical control of self-incompatibility in the species in question is more complex than it really is. It is perhaps worth emphasising that the misclassified pollinations and contaminant plants that have occurred in our own material were discovered precisely because the plants involved gave an impossible pattern of pollinations with others of the family, not merely on the two-locus model that we were attempting to fit to the data, but also on any other reasonable model. It was often possible to confirm the status of some of the contaminants (illegitimate selfs, pollen and seed contaminants) by determining their phenotypes for certain enzymes. While it is, of course, to be regretted that contamination of any type should occur, there is always a risk of illegitimate selfs when crosses are made without emasculation, as is customary with ryegrasses; and of contamination of crosses by foreign pollen in a species whose pollen is distributed by the wind. The chief point that needs to be made about this matter of analytical procedure is simply that, used properly, it is sufficiently sensitive to recognise misclassified pollinations and contaminant plants for what they are and hence to avoid the risk of concluding that self-incompatibility in ryegrass is controlled by more genes than are actually present.

Though we have been criticised by $\emptyset$ sterbye et al., (loc. cit.) for suspecting that Spoor's (1976) data on L. perenne contained unrecognised misclassification, there is no doubt about this in his most recent work. Thus in every family that McCraw and Spoor have examined, a proportion of the self-pollinations have been scored as self-compatible. Yet none of the 77 plants of $L$. rigidum set any seed when selfed and only one out of the 43 plants of $L$. multiflorum did so and this gave only seven seeds (McCraw and Spoor, 1983a). Again, though no less than 12 of the 23 plants in the $L$. perenne family were scored as self-compatible, only one set any seed (two, in fact) when selfed (McCraw and Spoor, 1983b). The seed-set results show that the plants of all three species are highly self-incompatible, for a seed-set of two or seven seeds only is very close to zero in percentage terms. Taking these results as a whole, then, 31 of the 143 plants that were selfed were scored as being self-compatible, which, in view of the seed-set obtained, indicates that 21 per cent of these selfs were misclassified. This proportion of misclassified pollinations is close to the percentages we have encountered in our own experiments. But in McCraw and Spoor's case, this figure is, of course, the proportion of self-incompatible pollinations that were scored as self-compatible. This is a much more serious form of misclassification than the kind we encountered where a proportion of half-compatible pollinations were scored as three-quarters compatible and vice versa. It is hardly unreasonable to suppose that a corresponding proportion of the crosses McCraw and Spoor have scored as compatible were, in truth, incompatible. Since the data of Spoor (1976) and of Hay 
(1978) also shows selfs that have been scored as self-compatible, none of this work can be regarded as trustworthy.

Third, their conclusion that self-incompatibility in their material is controlled by at least three loci is, at best, only marginally supported by their data, even if this is taken at face value. Thus the most striking feature of the results they have obtained from each of the eight families they have examined is that every plant falls into a unique class. Now the probability of obtaining a sample of size $n$ in which each plant is of unique genotype is

$$
P=\frac{N !}{(N-n) ! N^{n}} \quad(N \geqq n)
$$

where $N$ is the number of equally frequent classes in the population from which the sample has been drawn, $N$ being $4^{k}$, where $k$ is the number of loci in question. The probabilities of obtaining families of the sizes that Spoor and McCraw have examined, for $k=3$ and $k=4$, are shown in table 1 . Only one of the probabilities, that for $N=17$ and $k=4$, is anywhere near high enough to justify the conclusion drawn from the data.

TABLE 1

The probability of obtaining a sample of indicated size in which each member is unique and where the population contains $4^{k}$ equally frequent classes

\begin{tabular}{cccc}
\hline $\begin{array}{c}\text { Number of } \\
\text { families }\end{array}$ & $\begin{array}{c}\text { Size of } \\
\text { family }\end{array}$ & 3 & \multicolumn{2}{c}{ Number of loci } \\
\hline 1 & 17 & 0.09676 & 0.58098 \\
1 & 23 & $0 \cdot 01089$ & 0.36111 \\
2 & 25 & 0.00436 & 0.29785 \\
2 & 26 & 0.00266 & 0.26877 \\
1 & 27 & 0.00158 & 0.24147 \\
1 & 28 & 0.00091 & 0.2160 \\
\multicolumn{2}{r}{ Joint probability } & $2 \cdot 02973 \times 10^{-19}$ & $7 \cdot 01252 \times 10^{-5}$ \\
\hline
\end{tabular}

Furthermore, it is not unreasonable to suppose that the eight families examined can be regarded as independent samples that have been drawn from the same statistical population, so that we may calculate their joint probability; these, shown at the foot of table 1, leave virtually no doubt that these data cannot be explained on less than five genes, not three as they suppose. It is, of course, very doubtful whether systems of this complexity can be recognised with only one round of pollinations, even if it were possible to correctly classify these into all their grades. These calculations emphasise the danger of attempting to infer the genetical basis of a self-incompatibility system merely by counting the number of classes that occur in a family of practicable size.

Now any one of the three criticisms we have made would be sufficient to cast serious doubt on the soundness of the conclusions that Spoor and $\mathrm{McCraw}$ have drawn from their data; taken together, however, we have no choice but to reject both them and the data on which they are supposedly 
based. Though both Spoor and Lundqvist and his colleagues cite the work of Hayward and Wright (1971) in support of their belief that more than two genes are involved in the control of self-incompatibility in ryegrass, this has been obviously superseded by that of Cornish et al., loc cit., for reasons given by the latter. Furthermore, since Murray's (1979) work on Briza spicata is vulnerable to the same criticisms that we have made of that of Spoor and McCraw, claims that self-incompatibility is determined by more than two genes should be treated with considerable scepticism, not only for the genus Lolium, but also for the grasses in general.

In view of the evidence to the contrary, we find it difficult to understand why anybody should want to suppose that the determination of selfincompatibility in ryegrasses is more complex than it is. Thus, in our own experiments, we have never had much difficulty, once misclassified pollinations and contaminant plants have been recognised, in fitting a two-locus model to the data, and this classification was also supported by seed-set data. Again, the ease with which it has been possible to detect linkage between one of the incompatibility loci $(S)$ and a gene which codes for the enzyme, phosphoglucoisomerase $(P G I-2)$ removes any doubts about the accuracy of the classification of the plants upon which this conclusion is based (Cornish et al., 1980; Fearon et al., loc cit.). Lastly, the fact that it has been possible to fit a two-locus model to the data from an autotetraploid family of $L$. perenne, despite the complexities of inheritance and of expression that obtain at this ploidy level, strongly supports our conclusion that self-incompatibility in diploid ryegrass is controlled by two genes only (Scarrott, 1981).

\section{REFERENCES}

ABDAlla. M. M. F. AND hermSEN. J. G. Th. A two-loci system of gametophytic incompatibility in Solanum phureja and S. stenotomum. Euphytica, 20, 345-350.

CORNISH. M. A. 1979. The genetics of self-incompatibility in Lolium perenne. Ph.D. Thesis, University of Birmingham.

CORNISH. M. A., HAYWARD, M. D. AND LAWRENCE. M. J. 1979. Self-incompatibility in ryegrass. I. Genetic control in diploid Lolium perenne L. Heredity, 43, 95-106.

CORNISH. M. A.. HAYWARD, M. D. AND LAWRENCE, M. J. 1980. Self-incompatibility in ryegrass. III. The joint segregation of $S$ and $P G I-2$ in Lolium perenne L. Heredity, 44, 55-62.

CROWE, L. K. 1971. The polygenic control of outbreeding in Borago officinalis. Heredity, 27, 111-118.

FEARON. C. H. HAYWARD. M. D. AND LAWRENCE, M. J. 1983. Self-incompatibility in ryegrass. V. Genetic control, linkage and seed-set in diploid Lolium multiflorum Lam. Heredity, 50, 35-45.

HAY, J. M. 1978. Incompatibility in Lolium multiflorum. Incompatibility Newsletter, 10, 134136.

HAYMAN, D. C. 1956. The genetical control of incompatibility in Phalaris coerulescens Desf. Aust. J. Biol. Sci., 9, 321-331.

HAYWARD, M. D. AND WRIGHT. A. J. 1971. The genetic control of incompatibility in Lolium perenne L. Genetica, 42, 414-421.

LUNDQVIST, A. 1961. Self-incompatibility in Festuca pratensis Huds. Hereditas, 47, 542-562.

MCCRAW. J. M. AND SPOOR. W. 1983 a. Self-incompatibility in Lolium species. I. Lolium rigidum Gaud. and $L$. multiflorum L. Heredity, 50, 21-27.

McCRAW, J. M. AND SPOOR. W. 1983b. Self-incompatibility in Lolium species. II. Lolium perenne L. Heredity, 50, 29-33.

MURRAY, B. G. 1979. The genetics of self-incompatibility in Briza spicata. Incompatibility Newsletter, 11, 42-45. 
ØSTERBYE, U., LARSEN, K. AND LUNDQVIST, A. 1980. Comments on self-incompatibility in the Gramineae. Incompatibility Newsletter, 12, 45-49.

PANDEY, K. K. 1962, Genetics of incompatibility behaviour in the Mexican Solanum species S. pinnatisectum. Z. Vereb. Lehre., 93, 378-388.

SCARROTT, C. H. 1981. Self-incompatibility in diploid and tetraploid Lolium species. Ph.D. thesis, University of Birmingham.

SPOOR, w. 1976. Self-incompatibility in Lolium perenne L. Heredity, 37, 417-421.

VAROPOULOS, A. 1979. Breeding systems in Myosotis scorpioides L. (Boraginaceae). I. Self-incompatibility. Heredity, 42, 149-157. 